\title{
Narrative Health Communication
}

\author{
Hans Hoeken and Hanny den Ouden
}

\begin{abstract}
Narrative health interventions are considered potentially more effective than rhetorical health interventions as they are more likely to attract attention, be more comprehensible and memorable, and are less likely to evoke resistance. Metaanalyses reveal significant yet modest effects of narrative interventions on people's beliefs, attitudes, intentions, and behaviours. In this chapter, we will discuss the nature of narrative health interventions, the ways in which they can exert their impact, and the need to tailor these interventions to the target audience. For example, in a cyberbullying situation, narrative interventions focusing on perpetrators should tell a different story to those interventions focusing on victims. Further, neither of these targeted interventions should be the same as a communication aimed at bystanders who wish to intervene on behalf of victims.
\end{abstract}

\section{Introduction}

In January 2017 a leading Dutch newspaper carried the headline: "Cyberbullying, 15-year old boy committed suicide after being bullied on social media" (NRC, 10 January 2017). Once this was established as a focus of interest, the media began carrying more stories about the tragic consequences of cyberbullying. This book as a whole addresses the challenge of cyberbullying and argues for the value of narrative-based interventions to address the risks and the harms associated with this particular antisocial activity. This chapter does not so much address cyberbullying as the use of narrative methods to communicate health information with the aim of influencing beliefs, attitudes, intentions and behaviours. Although the chapter focusses on methods of communication, however, it uses cyberbullying examples in keeping with other chapters of the book.

H. Hoeken $(\varangle) \cdot$ H. den Ouden

UiL OTS, Utrecht University, Trans 10, 3512 JK Utrecht, The Netherlands

e-mail: j.a.l.hoeken@uu.nl

H. den Ouden

e-mail: h.denouden@uu.nl 
Cyberbullying is often presented as a young person's problem. Targets of cyberbullying are mostly school children and early adolescents, but they can include older adolescents and anyone who uses the internet, including senior citizens (Vandebosch \& Van Cleemput, 2009). Cyberbullying takes place through texting, and via apps, or online in social media, forums, or gaming contexts where people can view, participate in, or share content. It includes sending, posting, or sharing negative, harmful, false, or mean content about someone else, and sharing personal or private information about someone else that is likely to cause embarrassment or humiliation (Kowalski, Giumetti, Schroeder, \& Lattanner, 2014). Examples of cyberbullying are using someone's account or making false accounts in someone else's name, excluding someone from app-groups, distributing private photos or videos that involve someone else or that pretend to come from someone else, and sending threatening e-mails. Some cyberbullying is considered criminal behavior and can be prosecuted. All kinds of cyberbullying are social aggression and may result in harm to either or both the victim and the perpetrator (Vandebosch, Beirens, D’Haese, Wegge, \& Pabian, 2012).

Health communication information about cyberbullying is directed at both perpetrators and victims, as well as bystanders. Bystanders are other people who witness the cyberbullying, and can include class mates, parents, teachers, or unknown online audience members. Evidence-based information about cyberbullying is an example of health communication that can be targeted to speak to specific audiences. It makes people involved aware of the issue; it makes perpetrators aware of the impacts of their bullying behavior; and, provides victims, parents and teachers with directions about preventing or dealing with the cyberbullying events. In this chapter our focus is on explaining how narrative health communication works and how narrative communication can influence people's awareness and behaviour. We will discuss how narrative communication can be used in the case of cyberbullying.

\section{Narrative Versus Paradigmatic Thinking}

Bruner (1986, p. 11) distinguishes between two modes of thinking, "each providing distinctive ways of ordering experience, of constructing reality", using the labels "paradigmatic thinking" and "narrative thinking" for these different modes. The paradigmatic mode of thinking aims to provide accurate descriptions and explanations of general phenomena using categorisation and logic: it helps order experience. A strong application of this mode of thought "leads to good theory, tight analysis, logical proof, sound argument, and empirical discovery guided by reasoned hypothesis" (Bruner, 1986, p. 13). The narrative mode of thinking, on the other hand, deals with the particular rather than the general, with human goals and human action, as well as the consequences of these actions. It helps people construct their understanding of reality: why things happen the way they do, and how to prevent bad things happening and make good things more likely. As such, the narrative mode of thinking leads to "good stories, gripping drama, believable (though not necessarily 'true') historical accounts" (Bruner, 1986, p. 13). 
These two modes of thought result in different types of discourse when they are verbalised. Paradigmatic thought results in rhetorical discourse (or argument), whereas narrative thought gives rise to story-telling and narrative discourse. Bruner (1986, p. 11) succinctly describes the deep divide between these types of discourse: "A good story and a well-formed argument are different natural kinds". Both types of discourse are used extensively in health communication in general, and can be used in communication about cyberbullying as well. Rhetorical discourse offers arguments that aim to change the beliefs people have about the likelihood that certain actions will have certain effects. An example of such a cause and effect argument might be that: sending, posting, or sharing harmful content about someone else on the internet cannot be undone. Rhetorical discourse is also used to convince a target audience about the undesirability of certain consequences. A relevant message might be: cyberbullying can harm the online reputations of everyone involved-not just the person being bullied, but also those doing the bullying, and those that take part in it. Rhetoric can also be used to provide information for a target audience about the desirability of intervening to avoid other consequences. This might include, for example, materials for parents or teachers to help them recognize signs of a child who is being cyberbullied, or who is cyberbullying others. Finally, rhetorical discourse may focus on the beliefs that people have about the feasibility of the behaviour being promoted, for instance, raising awareness and knowledge of parents and teachers about how recognising victims and perpetrators will help to prevent cyberbullying among children.

The extent to which rhetorical discourse will lead to stable and predictable behavioural change is believed to depend on the extent to which the target audience accepts the message and the claimed impact of a changed behaviour or response. This involves the message receiver in a careful evaluation of the arguments (Petty \& Cacioppo, 1986), since rhetorical discourse engages cognitive faculties, rather than emotions. From this perspective, sound arguments are thus crucial to a rhetorical message's success, and indeed, people are sensitive to the extent to which arguments meet normative criteria and seem valid. (See Hoeken (2017) for a review of how arguments can play a role in health communication.)

In this chapter, however, we are focussing on narrative communication methods. This is the second type of Bruner's (1986, p. 11) discourse, resulting from and relating to narrative thinking: telling stories and engaging the listener's, reader's or viewer's emotions. Cyberbullying is often reflective of a power struggle, of individuals who might feel inside or outside a group, powerful or powerless in different circumstances. These are emotional situations, not rational ones. Consequently, a narrative approach may be more suitable for communicating about cyberbullying than a rhetorical approach. A rhetorical argument that deals with the logic of a situation may be less relevant for preventing and dealing with cyberbullying than stories about perpetrators, or victims, of cyberbullying.

As this chapter develops, we will offer and discuss evidence for narratives being able to influence people's beliefs, attitudes, intentions, and behaviour. Next, we discuss the models that have been developed to explain how narratives exert their impact. Subsequently, we focus on how to identify relevant targets for narrative interventions, 
depending on the characteristics of the target audience, and their willingness and readiness to change. Finally, we discuss how narratives can be tailored to address the specific targets they aim to change. But first, we will discuss what a narrative is.

\section{What Is a Narrative?}

Toolan (2001, p. 8) defines a narrative as "a perceived sequence of non-randomly connected events, typically involving, as the experiencing agonist, humans or quasihumans, or other sentient beings, from whose experience we humans can 'learn"'. From this definition, it follows that a narrative consists of at least two events that are (chronologically or causally) related to each other. A narrative health intervention, for instance, would include a story about a teenager who uses sunbeds to get a tan (event 1) and develops skin cancer (event 2); or a truck driver who aims to get more exercise (event 1), starts riding a bike to work (event 2), and thus gets fitter (event 3 ). In addition, the narrative includes an experiencing agonist (the teenager in the first example, the truck driver in the second) who provides insights into how the consequences are experienced (the teen) or how one can go about reaching one's goals (the truck driver). Thus, the audience can learn vicariously from these actions and experiences.

Bruner (1986) argues that stories simultaneously develop two related landscapes: the landscape of action, and the landscape of consciousness. The landscape of action is about goals, agents, instruments, and the consequence of using these instruments to attain these goals. The landscape of consciousness is about "what those involved in the action know, think, or feel or do not know, think, or feel" (Bruner, 1986, p. 14). Relating these two landscapes to Toolan's definition of a narrative, it appears that the landscape of narrative action is about the realm of goals, actions and their consequences, thereby sketching the events and ways in which they are related. The landscape of consciousness provides insight into what the agonist is experiencing. Although each story creates both landscapes, stories may differ in the extent to which a landscape is elaborated. For cyberbullying it may be imaginable to create stories about the actions a perpetrator performs and the consequences they have as well as to create separate stories about the psychological stress and pain a victim experiences.

The label "narrative" can be applied to a wide range of phenomena. Narratives can be told through different media - print, fotonovelas, auditory, audio-visual or in games. They can be based on facts or (partly) made up by their authors. They can be told in a long running radio or television series, single movies, books, in short stories, or via a comic strips. 


\section{Narrative Impact}

In the twentieth century, research on persuasion focused mainly on the impact of various dimensions of rhetorical messages on attitudes (e.g., argument quality, source characteristics, images). At the end of that century, and at the start of the new one, studies were published showing that, in addition to argument, stories can be used to influence people's opinions, attitudes, and behaviour. (See, e.g., Green \& Brock, 2000; Strange \& Leung, 1999.) In subsequent research, it was found that the effects of stories were relatively stable over time (Appel \& Richter, 2007), and did not depend on whether the narrative was presented as a true story or one that was made up (Appel \& Maleckar, 2012; Green \& Brock, 2000).

Since then, many studies have been conducted on the persuasive impact of narrative. In a meta-analysis, Braddock and Dillard (2016) analysed the results of 74 studies in which the persuasiveness of a narrative was compared to the effects of an equivalent non-narrative message, or a control group. They report relatively small $(0.17<r<0.23)$, yet statistically significant, effects of narratives on people's beliefs, attitudes, intentions, and behaviour. Thereby, Braddock and Dillard (2016) provide strong evidence for a narrative's potential to persuade its audience.

The models of persuasion that had been developed to explain how rhetorical communication influenced people's attitudes and behaviour were deemed incapable of explaining how stories achieve their impact. For example, in models such as the Elaboration Likelihood Model (Petty \& Cacioppo, 1986) it is believed that people who are highly involved in processing a rhetorical message scrutinise the arguments involved. This careful evaluation of the message content is considered time and effort consuming, and will only occur if people are sufficiently motivated to spend the time and are able to follow the logic of the argument. The ultimate outcome of the persuasion process depends in this case on the audience's take on the quality of the arguments presented in the message. In contrast, people usually find it much easier to become involved in a story than in a rhetorical text. Gerrig (1993) introduced the term "transportation" for the experience of being lost in a book; the sense that the world evoked in the narrative is more real at that point than the world in which the reader is reading this book. Green and Brock (2000, p. 701) defined transportation as "a distinct mental process, an integrative melding of attention, imagery, and feelings", that functions as the main driver of narrative persuasion. The more the audience is transported into the story world, the more likely it is to develop story-consistent beliefs and attitudes.

Several models have been developed to explain the narrative persuasion process (see, Green \& Brock, 2002; Moyer-Gusé, 2008; Slater \& Rouner, 2002). All models agree on the feeling of being lost in the story as an important driver of this process, and various mechanisms have been proposed to explain how this experience can yield changes in attitudes and behaviour. One explanation is that narratives are less likely to evoke resistance and counter-arguing compared to rhetorical messages. The persuasive intent of the latter is often recognised by the audience and perceived as a threat to its autonomy, leading to active counter-arguing. Narratives, on the other 
hand, are less likely to be perceived as intentional efforts to influence the audience's attitudes and are therefore less likely to evoke this type of resistance. In addition, people often read or watch narratives for enjoyment. As Slater (2002) argues, actively engaging in critical thinking is detrimental to this goal.

The possibility of counter-arguing helps explain why rhetorical messages may fail, but not how narratives might succeed in changing people's attitudes. One explanation for the positive effects of narrative is that stories can evoke-or provide, or trigger-vivid depictions of certain events. These lifelike portrayals of events can influence people's estimation of the likelihood of the event occurring. As a result, people may change their beliefs about for instance the safety of flying after being exposed to a story about an air crash (Green \& Brock, 2002), or feel motivated to adopt safe sex practices after processing a narrative about a person getting a sexually transmitted disease (Moyer-Gusé, 2008).

Narratives have also been hypothesized to persuade through the bond the audience develops with the story characters. This attachment to the characters is usually referred to as identification. Cohen (2001) describes identification as consisting of the ability to feel what the character feels (emotional empathy), adopting the character's point of view (cognitive empathy), internalizing the character's goal, and potentially having the sensation of becoming the character. Green and Donahue (2009, p. 247) argue that because of identification with a character, "statements made by the character or implications of events experienced by that character may carry special weight" in shifting a reader's attitude. In addition, the story character can serve as a role model providing the audience with an example of how to deal with certain situations (Hoeken \& Geurts, 2005; Moyer-Gusé, 2008). The persuasive impact of a story can thus be the result of different mechanisms, and may combine several approaches in achieving its effect.

\section{Narratives in Health Communication}

Soon after the persuasion potential of narratives had been established, several papers were published on the use of narratives in health interventions, both in a more general sense (Hinyard \& Kreuter, 2007), and also within the context of specific communication about, for example, cancer (Green, 2006; Kreuter et al., 2007). The general thrust of these articles is that narrative interventions can serve as positive ways to foster health-promoting activity because, as previously outlined, they: reduce counterarguing; offer vivid depictions; engage the emotions; and provide characters with whom the audience can relate, and who can also serve as role models.

In addition, narrative interventions may facilitate the processing of health information. Kreuter et al. (2007) argue that narrative interventions are (1) more likely to attract the target audience's attention because stories are more fun to process than rhetorical messages, (2) easier to comprehend because people's lifelong experience in processing stories has equipped them with elaborate cognitive schemes for responding to story structures, (3) and, because of these cognitive schemes, enabling 
audiences to remember story information more efficiently. The relative ease with which narratives can be comprehended and recalled, when compared to rhetorical messages, is especially important when aiming to reach a less 'health literate' audience. Health literacy refers to people having "the cognitive and social skills which determine the motivation and the ability of individuals to gain access to, understand and use information in ways which promote and maintain good health" (WHO, 1998). Lower health literacy is related to lower socio-economic status, which is often linked to lower levels of education and fewer life choices, which are also related to living a shorter life, with fewer years lived in good health. People with lower health literacy are thus the ones who could benefit most from effective health interventions. However, many health interventions do not appear to be tailored to their processing capacities and life experiences. For instance, Boeijinga, Hoeken, and Sanders (2017a) found that interventions targeting the unhealthy lifestyle of many Dutch truck drivers mainly consisted of print messages containing implicit arguments. For these interventions to be effective, truck drivers need to infer the hidden premises, identify the type of argument involved, and apply the relevant criteria to assess the argument's strength, thereby posing high demands on the truck drivers' cognitive capacities as well as assuming motivation to process the message, prior to developing a motivation to adopt changed behaviour.

A number of studies have been conducted to assess whether narrative health interventions can change people's attitudes and behaviour more effectively than rhetorical approaches. Murphy, Frank, Chatterjee, and Baezconde-Garbanati (2013), for instance, carefully compared the impact of an audio-visual narrative to a rhetorical one and found the narrative to be more effective in increasing women's knowledge of and attitudes towards cervical cancer. Moyer-Gusé and Nabi (2010) showed how watching an episode of a television series influenced adolescents' attitudes towards teen pregnancy and their intentions to have safe sex. Boeijinga et al. (2017b) found that stories about a truck driver who suffered a heart attack led other truck drivers to form more positive intentions towards exercising more. Shen, Sheer, and Li (2015) conducted a meta-analysis of 25 studies in a health communication context reporting a small, yet statistically reliable, persuasive effect of narratives. For a better understanding of how narrative health interventions exert their impact, it is important to understand what the determinants of health behaviour are.

\section{Determinants of Health Behaviour}

Health interventions can have various goals: they may seek to raise awareness of an issue, provide information on causes or treatment of diseases, or change attitudes and intentions in order to change health-related behaviour. The extent to which a narrative intervention is successful may depend on the extent to which the story characteristics are attuned to the specific audience targeted by the intervention. To understand how tuning can be successful, it is important to know which behavioural determinants underlie the processing of specific health interventions. 
Basically, there are two types of models for explaining the main determinants of behaviour. On the one hand, there are models such as Fishbein and Yzer's (2003) integrative model of behavioural prediction. In these models, actual behaviour is said to depend on (1) the intention to perform the behaviour, (2) barriers that prevent people from putting their intention into action, and (3) the person's skills to perform the action. The individual's intention is, in turn, determined by the person's evaluation of the behaviour (his or her attitude), the extent to which a person believes that the behaviour is approved by others (the perceived norm), and the extent to which the person considers the behaviour as feasible for them to adopt (self-efficacy). Selfefficacy here refers to the notion that people see themselves as having greater or lesser control (more or less self-efficacy) in terms of how capable they are of responding effectively to specific challenges and situations (Bandura, 1997). In research using these models, changes in the intention to perform the behaviour are considered proof that the intervention has been successful. However, there is considerable evidence for the existence of a gap between the intention and the related behavioural action (Webb \& Sheeran, 2006). That is, despite a campaign's success in changing intentions, the subsequent change in behaviour is often modest or absent. With respect to the relation between intention and health behaviours, people were found to act effectively upon their intentions in only $53 \%$ of cases (Sheeran, 2002). Although the intention to change may be a prerequisite for subsequent behaviour change, it is far from being sufficient to cause such change.

In contrast, a second type of model focuses on the various stages of change a person has to go through when changing behaviour. In his Health Action Process Approach (HAPA), Schwarzer (2008) distinguishes between non-intenders, who indeed need to be motivated to change their lifestyle, and intenders, who already intend to adopt a healthier lifestyle but have failed to put this intention into action. According to the HAPA-model, the lack of motivation of the non-intenders is the result of three factors: (1) the extent to which people feel at risk because of their current unhealthy lifestyle (risk perception), (2) their expectations about the outcomes of adopting the advocated behaviour (outcome expectancies), and (3) the extent to which they feel capable of carrying out the behaviours (self-efficacy). For the intenders, a different picture arises. They are already convinced of the undesirability of their current lifestyle and hold favourable expectations about the alternative behaviour but have not yet put their intention into action because they (1) fail to get started or (2) are unable to navigate obstacles.

This distinction is relevant when considering narrative interventions concerning cyberbullying since perpetrators, victims and bystanders can all include both nonintenders and intenders. Narrative interventions should make non-intenders aware of the problem of cyberbullying and the dangers it poses for both perpetrators and victims, whereas intenders should be assisted in developing strategies for avoiding, signalling or stopping cyberbullying.

Schwarzer (2008) argues that turning non-intenders into actors requires a different communication strategy compared with turning intenders into actors. Non-intenders need to be motivated to change their behaviour. That is, communication to perpetrators should aim to convince them that their health, or the health of their victims, 
is at risk if they continue their current behaviour (increase risk perception), that the advocated behaviour on the whole will have positive outcomes for their victims, but also for themselves (outcome expectancies), and that the behaviour is feasible and within their capacity (self-efficacy).

Intenders, on the other hand, need help to get started in adopting specific interventions that they can put into action. This can be accomplished by urging intenders to develop concrete plans on when, where, and with whom to conduct the altered behaviour. Communication about cyberbullying directed to teachers, for example, could be focussed on instructions about how to make cyberbullying a subject of discussion in the class room, or how to handle perpetrators, and support victims. Communication directed to victims should be focussed on seeking help or support, and other effective actions and strategies to avoid, mitigate or stop the cyberbullying behaviours. This formation for implementing specific intentions is called action planning. In addition, providing intenders with strategies as to how to deal effectively with barriers to implementation may help them put intentions into action. The development of such strategies is called coping planning. Schwarzer (2008) shows that health interventions should address different determinants, depending on whether the target audience consists of intenders or non-intenders.

\section{Different Targets Need Different Stories}

Given any single topic, a myriad of different stories can be told. In the case of cyberbullying, a narrative intervention could focus on the experiences of a victim, but also on how a former victim succeeded in putting an end to being cyberbullied. Or the narratives could tell the story of the more (and less) successful strategies employed by bystanders who intervened on behalf of a victim, becoming 'upstanders' (Blumenfeld \& Cooper, 2010, p. 128). They could tell the story of teachers or parents who successfully picked up signs of cyberbullying or failed to notice them. This list is by no means exhaustive; many more stories could be invented according to the narrative intention and the intended audience.

The variation among the suggested stories stems from at least two important factors: the characters involved and the events they experience. These characters are the "experiencing agonists" in Toolan's (2001) definition of a narrative. For these characters, the audience will get a fair amount of insight of their landscape of consciousness: What are their goals, what are their intentions, and how do they evaluate the situations they find themselves in? The same events can be experienced from different perspectives; they can be told from the victim's, the perpetrator's, or the bystanders' perspective.

Equally important is the landscape of action depicted in the story events. Are those events about the (undesirable) consequences of certain actions, or about the (desirable) consequences of changed behaviour? Do they address strategies about dealing with obstacles that prevent people from attaining their goals? Whether a narrative intervention will be effective is likely to depend on the match between the 
story told and the desired behavioural responses. Below, we specify what appear to be plausible connections between these factors.

\subsection{Targeting Risk Perceptions and Outcome Expectancies for Non-intenders}

As discussed in Sect. 6, two important determinants of the intention to change one's behaviour are the perceived risk of the current behaviour and the expected outcomes of the advocated behaviour change. In both cases, the underlying structure is the same: A certain line of action may have specific consequences and these consequences are evaluated as good or bad. Successful narrative interventions are those that make people believe that a certain effect will occur as a result of their actions. Narratives may also succeed in clarifying the desirability (in the case of outcome expectancies) or the undesirability (in the case of perceived risk) of the resulting situation. For example, perpetrators who consider their behaviour to be an innocent prank and thus qualify as non-intenders, need to be convinced of the far reaching consequences that cyberbullying may have, and may need to realise that they are wrong to believe that their behaviour is innocent.

With respect to the perceived likelihood of events, the extent to which the narrative evokes a vivid image of an event could play a role in motivating behaviour change in non-intenders (Green \& Brock, 2002; Kahneman, 2011, pp. 326-331). The concreteness of the depiction of the consequence, as well as the ease with which this depiction can be evoked, may influence to what extent the non-intenders consider this consequence likely to occur. Several studies have revealed such effects for non-intenders. Dillard, Fagerlin, Dal Cin, Zikmund-Fisher, and Ubel (2010) reported that a narrative message, compared to a rhetorical message, increased perceived risk for colorectal cancer. Similar findings have been obtained for risk perceptions with respect to hepatitis B (De Wit, Das, \& Vet, 2008), influenza (Prati, Pietrantoni, \& Zani, 2012), and sexually transmitted diseases (So \& Nabi, 2013). With respect to cyberbullying, a vivid depiction of a victim's experiences may change perpetrators' ideas about their behaviour being an innocent prank.

People may also develop beliefs about events based upon the views held by the story characters with whom they identify (Green \& Donahue, 2009). A number of studies have shown that when people identify with a certain character, they are more likely to adopt that character's opinions and beliefs [see, e.g., De Graaf, Hoeken, Sanders, and Beentjes (2012); Hoeken, Kolthoff, and Sanders (2016)], even when the character expresses opinions that go against the participants' interests (Hoeken \& Fikkers, 2014). Identification can thus play an important role in the formation and change of beliefs. For example, identification with a victim in a story who succeeds in stopping the cyberbullying may change a victim's belief in his or her own selfefficacy. 
Narratives can also play an important role in influencing the perceived desirability of an event through the emotions they evoke. Narratives can make us happy, sad, angry or content: they communicate at an emotional level. The intensity and the valence of these emotions are important: the emotional response has been proved in several studies to be the best predictor of a narrative's persuasive impact (Busselle \& Bilandzic, 2009; De Graaf et al., 2009). These emotions typically arise as a result of the story characters' vicissitudes (Oatley, 1999). If the cyberbullied character succeeds in stopping the actions of a perpetrator, positive feelings are evoked; if he or she fails, sadness or anger may be the result. Again, the more strongly the audience identifies with a character, the more intense these emotions become, and the stronger the impact the narrative has on the audience's opinions (Hoeken \& Sinkeldam, 2014). Thus, the process of identification, and the emotions evoked by the story, may lead to a change in non-intenders' risk perceptions, and impact their outcome expectancies.

\subsection{Targeting Action and Coping Planning Strategies for Intenders}

For intenders, narrative health interventions should focus on the development of planning strategies that help them to put their intention into action. This requires information on how to develop implementation intentions (action planning) and/or how to deal with obstacles (coping planning). This information may also be relevant for non-intenders as well, as it can improve their perception of self-efficacy.

Narrative health interventions may be especially appropriate in helping to improve the target audience's planning strategies. Stories are often about a character who has a certain goal (e.g., to step up to help a class mate). In order to attain that goal the character has to conquer certain obstacles (e.g., how to deal with peer pressure) (Campbell, 1972). According to Bandura's (1977) social cognitive theory, people can learn relevant behaviours by observing other people's behaviour. Consequently, the character in a story can serve as a role model. Especially when the character is successful in navigating anticipated obstacles, the audience may become more confident that it will also be able to achieve this outcome. This effect on self-efficacy may be stronger when the audience identifies with the character (Moyer-Gusé, 2008).

Moyer-Gusé, Chung, and Jain (2011) provide evidence for this effect in a study on the impact of narratives on people's intention to talk about taboo topics relating to sexual health. They explain this effect by the narrative's capacity to provide a scenario on how to bring up such topics in conversation. Boeijinga et al. (2017b) found a similar effect in a narrative health intervention in which a truck driver relates how he has succeeded in including more exercise in his daily routines. Truck drivers reading or listening to this story developed more positive planning beliefs and the intention to exercise more. When a teacher suspects that cyberbullying is going on in his or her class room, and intends to do something about this, he or she could show a narrative movie about cyberbullying that makes it possible for the class to discuss 
the subject. This might also provide perpetrators, bystanders and victims with useful tools to handle the problem in real life.

\section{Conclusion}

Meta-analyses have revealed that narrative health interventions can influence people's opinions and behaviours. The effects, however, are modest. Stronger effects may be possible if the narratives are tailored to the determinants that inhibit an audience from acting in the advocated manner. Where the audience still needs to be motivated to act, stories should focus on the likelihood that certain behaviour leads to certain consequences, and what such consequences entail. For audiences that are already motivated to change their behaviour, stories should provide role models that employ the strategies that enable people to put their intentions into action. This distinction means that audiences that do not intend to change their behaviours, should watch or read stories about victims and the impact cyberbullying has on their daily lives. Audiences that are already aware of this impact but do not know how to stop cyberbullying, or how to help someone who is being cyberbullied, should watch or read stories of characters who have succeeded in stopping the cyberbully, or helped in some interim way. In all these cases, narrative health communication about cyberbullying is likely to be more effective than an equivalent rhetorical health communication.

\section{References}

Appel, M., \& Maleckar, B. (2012). The influence of paratext on narrative persuasion: Fact, fiction, or fake? Human Communication Research, 38(4), 459-484. https://doi.org/10.1111/j.1468-2958. 2012.01432.x.

Appel, M., \& Richter, T. (2007). Persuasive effects of fictional narratives increase over time. Media Psychology, 10(1), 113-134. https://doi.org/10.1080/15213260701301194.

Bandura, A. (1977). Self-efficacy: Toward a unifying theory of behavioral change. Psychological Review, 84(2), 191-215. https://doi.org/10.1037/0033-295x.84.2.191.

Bandura, A. (1997). Self-efficacy: The exercise of control. New York: W. H. Freeman.

Blumenfeld, W. J., \& Cooper, R. M. (2010). LGBT and allied youth responses to cyberbullying: Policy implications. International Journal of Critical Pedagogy, 3(1), 114-133.

Boeijinga, A., Hoeken, H., \& Sanders, J. (2017a). An analysis of health promotion materials for Dutch truck drivers: Off target and too complex? Work, 56(4), 539-549.

Boeijinga, A., Hoeken, H., \& Sanders, J. (2017b). Risk versus planning health narratives targeting Dutch truck drivers: Obtaining impact via different routes? International Journal of Communication, 11, 5007-5026.

Braddock, K. H., \& Dillard, J. P. (2016). Meta-analytic evidence for the persuasive effect of narratives on beliefs, attitudes, intentions, and behaviors. Communication Monographs, 83(4), 446-467. https://doi.org/10.1080/03637751.2015.1128555.

Bruner, J. (1986). Actual minds, possible worlds. Cambridge, MA: Harvard University Press.

Busselle, R., \& Bilandzic, H. (2009). Measuring narrative engagement. Media Psychology, 12(4), 321-347. https://doi.org/10.1080/15213260903287259. 
Campbell, J. (1972). The hero with a thousand faces (1949). Novato, California: New World Library.

Cohen, J. (2001). Defining identification: A theoretical look at the identification of audiences with media characters. Mass Communication and Society, 4, 245-264.

De Graaf, A., Hoeken, H., Sanders, J., \& Beentjes, J. (2009). The role of dimensions of narrative engagement in narrative persuasion. Communications, 34(4), 385-405.

De Graaf, A., Hoeken, H., Sanders, J., \& Beentjes, J. (2012). Identification as a mechanism of narrative persuasion. Communication Research, 39(6), 802-821. https://doi.org/10.1177/ 0093650211408594.

De Wit, J. B., Das, E., \& Vet, R. (2008). What works best: Objective statistics or a personal testimonial? An assessment of the persuasive effects of different types of message evidence on risk perception. Health Psychology, 27(1), 110-115. https://doi.org/10.1037/0278-6133.27.1. 110.

Dillard, A. J., Fagerlin, A., Dal Cin, S., Zikmund-Fisher, B. J., \& Ubel, P. A. (2010). Narratives that address affective forecasting errors reduce perceived barriers to colorectal cancer screening. Social Science and Medicine, 71(1), 45-52. https://doi.org/10.1016/j.socscimed.2010.02.038.

Fishbein, M., \& Yzer, M. C. (2003). Using theory in developing effective health behaviour interventions. Communication Theory, 14(2), 164-183.

Gerrig, R. J. (1993). Experiencing narrative worlds: On the psychological activities of reading. Yale University Press.

Green, M. C. (2006). Narratives and cancer communication. Journal of Communication, 56(s1), S163-183. https://doi.org/10.1111/j.1460-2466.2006.00288.x.

Green, M. C., \& Brock, T. C. (2000). The role of transportation in the persuasiveness of public narratives. Journal of Personality and Social Psychology, 79(5), 701-721. https://doi.org/10. 1037//0022-3514.79.5.701.

Green, M. C., \& Brock, T. C. (2002). In the mind's eye: Transportation-imagery model of narrative persuasion. In T. C. Brock, J. J. Strange, \& M. C. Green (Eds.), Narrative impact: Social and cognitive foundations (pp. 315-341). Mahwah, NJ: Erlbaum.

Green, M. C., \& Donahue, J. K. (2009). Simulated worlds: Transportation into narratives. In K. Markman, W. M. Klein, \& J. A. Suhr (Eds.), Handbook of imagination and mental simulation (pp. 241-254). New York, NY: Taylor \& Francis Group.

Hinyard, L. J., \& Kreuter, M. W. (2007). Using narrative communication as a tool for health behavior change: A conceptual, theoretical, and empirical overview. Health Education and Behavior, 34(5), 777-792. https://doi.org/10.1177/1090198106291963.

Hoeken, H. (2017). Argument quality and strength in health and risk messaging. In R. Parrott (Ed.), Oxford research encyclopedia of communications-Oxford encyclopedia of health and risk message design and processing (pp. 1-26). Oxford: Oxford University Press.

Hoeken, H., \& Fikkers, K. M. (2014). Issue-relevant thinking and identification as mechanisms of narrative persuasion. Poetics, 44, 84-99. https://doi.org/10.1016/j.poetic.2014.05.001.

Hoeken, H., \& Geurts, D. (2005). The influence of exemplars in fear appeals on the perception of self-efficacy and message acceptance. Information Design Journal \& Document Design, 13(3), $238-248$.

Hoeken, H., Kolthoff, M., \& Sanders, J. (2016). Story perspective and character similarity as drivers of identification and narrative persuasion. Human Communication Research, 42(2), 292-311. https://doi.org/10.1111/hcre.12076.

Hoeken, H., \& Sinkeldam, J. (2014). The role of identification and emotion and perception of just outcome in evoking emotions in narrative persuasion. Journal of Communication, 64(5), 935-955. https://doi.org/10.1111/jcom.12114.

Kahneman, D. (2011). Thinking, fast and slow. London: Penguin.

Kowalski, R. M., Giumetti, G. W., Schroeder, A. N., \& Lattanner, M. R. (2014). Bullying in the digital age: A critical review and meta-analysis of cyberbullying research among youth. Psychological Bulletin, 140(4), 1073-1137.

Kreuter, R. W., Green, M. C., Cappella, J. N., Slater, M. D., Wise, M. E., Storey, D., \& Woolley, S. (2007). Narrative communication in cancer prevention and control: A framework to guide 
research and application. Annals of Behavioral Medicine, 33(3), 221-235. https://doi.org/10. 1007/bf02879904.

Moyer-Gusé, E. (2008). Toward a theory of entertainment persuasion: Explaining the persuasive effects of entertainment-education messages. Communication Theory, 18(3), 407-425. https:// doi.org/10.1111/j.1468-2885.2008.00328.x.

Moyer-Gusé, E., Chung, A. H., \& Jain, P. (2011). Identification with characters and discussion of taboo topics after exposure to an entertainment narrative about sexual health. Journal of Communication, 61(3), 387-406. https://doi.org/10.1111/j.1460-2466.2011.01551.x.

Moyer-Gusé, E., \& Nabi, R. L. (2010). Explaining the effects of narrative in an entertainment television program: Overcoming resistance to persuasion. Human Communication Research, 36(1), 26-52. https://doi.org/10.1111/j.1468-2958.2009.01367.x.

Murphy, S., Frank, L. B., Chatterjee, J. S., \& Baezconde-Garbanati, L. (2013). Narrative versus nonnarrative: The role of identification, transportation, and emotion in reducing health disparities. Journal of Communication, 63(1), 116-137. https://doi.org/10.1111/jcom.12007.

NRC. (2017, January 11). 15-years old boy commited suicide 'cause of cyberbullying'. Retrieved from https://www.nrc.nl/nieuws/2017/01/11/heerlense-scholier-pleegt-zelfmoord-ompesterijen-6159546-a1540722.

Oatley, K. (1999). Meeting of minds: Dialogue, sympathy and identification in reading fiction. Poetics, 26, 454-493.

Petty, R. E., \& Cacioppo, J. T. (1986). Communication and persuasion. Central and peripheral routes to attitude change. Berlin: Springer.

Prati, G., Pietrantoni, L., \& Zani, B. (2012). Influenza vaccination: The persuasiveness of messages among people aged 65 years and older. Health Communication, 27(5), 413-420. https://doi.org/ $10.1080 / 10410236.2011 .606523$.

Schwarzer, R. (2008). Modeling health behavior change: How to predict and modify the adoption and maintenance of health behaviors. Applied Psychology, 57(1), 1-29. https://doi.org/10.1111/ j.1464-0597.2007.00325.x.

Sheeran, P. (2002). Intention-behavior relations: A conceptual and empirical review. European Review of Social Psychology, 12(1), 1-36. https://doi.org/10.1080/14792772143000003.

Shen, F., Sheer, V. C., \& Li, R. (2015). Impact of narratives on persuasion in health communication: A meta-analysis. Journal of Advertising, 44(2), 105-113. https://doi.org/10.1080/00913367.2015. 1018467.

Slater, M. D. (2002). Entertainment education and the persuasive impact of narratives. In M. C. Green, J. J. Strange, \& T. C. Brock (Eds.), Narrative impact: Social and cognitive foundations (pp. 157-181). Mahwah, NJ: Erlbaum.

Slater, M. D., \& Rouner, D. (2002). Entertainment-education and elaboration likelihood: Understanding the processing of narrative persuasion. Communication Theory, 12, 173-191.

So, J., \& Nabi, R. (2013). Reduction of perceived social distance as an explanation for media's influence on personal risk perceptions: A test of the risk convergence model. Human Communication Research, 39(3), 317-338. https://doi.org/10.1111/hcre.12005.

Strange, J. J., \& Leung, C. C. (1999). How anecdotal accounts in news and in fiction can influence judgments of a social's problem urgency, causes, and cures. Personality and Social Psychology Bulletin, 25, 436-449.

Toolan, M. (2001). Narrative: A critical linguistic introduction (2nd ed.). London: Routledge.

Vandebosch, H., \& Van Cleemput, K. (2009). Cyberbullying among youngsters: Profiles of bullies and victims. New Media Society, 11(8), 1349-1371.

Vandebosch, H., Beirens, L., D’Haese, W., Wegge, D., \& Pabian, S. (2012). Police actions with regard to cyberbullying: The Belgian case. Psicothema, 24(4), 646-652.

Webb, T. L., \& Sheeran, P. (2006). Does changing behavioral intentions engender behavior change? A meta-analysis of the experimental evidence. Psychological Bulletin, 132(2), 249-268. https:// doi.org/10.1037/0033-2909.132.2.249.

World Health Organization (WHO). (1998). Health promotion glossary. Retrieved from http://www. who.int/healthpromotion/about/HPR\%20Glossary\%201998.pdf. 